\title{
Afterword: Mobile Law and Thick Transregionalism
}

\author{
ENGSENG HO
}

The articles in this special issue of Law and History Review advance Indian Ocean studies and legal history by employing innovative mobile methods and concepts. In the past few decades, the Indian Ocean has become established as a frame for research and an object of study in its own right. Inspired by Braudel's work on the Mediterranean, and alert to geography, pioneering economic and political historians established the ocean's worth as a field of research. ${ }^{1}$ More recently, understanding of the ocean and its histories and societies has been broadened to include fields such as religion, diaspora, cultural history, literature, and the environment. ${ }^{2}$

Although the European empires and the archives they left behind provide substantial primary sources and frames of interpretation, used by economic and political historians to good effect, non-European sources and points of view are increasingly being mobilized, feeding into a broader view of the Indian Ocean. The articles in this issue reflect this mix of sources and viewpoints, while building a major new dimension in Indian Ocean studies-that of law-pioneered by Charles Alexandrowicz, Lauren Benton, and Thomas Metcalf.

1. As in the writings of Kirti N. Chaudhuri, Ashin Das Gupta, Michael Pearson, Sanjay Subrahmanyan, Thomas Metcalf, and others.

2. See the recent works by Sunil Amrith, Sebouh Aslanian, Sugata Bose, Nile Green, Engseng Ho, Piers Larson, Sheldon Pollock, Ronit Ricci, Tansen Sen, and Abdul Sheriff.

Engseng Ho is Professor of History and Professor of Anthropology at Duke University, and Muhammad Alagil Distinguished Visiting Professor of Arabia Asia Studies at the Asia Research Institute, National University of Singapore. email: engseng.ho@duke.edu 
Law's contribution to Indian Ocean studies is one that is both powerful and subtle. Its reach stretches from the visible heights of formal political power to the unnoticed depths of everyday life. Law draws on religious and cultural sources, while helping to enable and shape economic relations among different communities: imperial, native, and diasporic. Law provides language for such exchanges, and for the security protections that stand behind them. Because these exchanges are substantially embedded in material interests, legal documents can offer the researcher primary sources that are incremental and cumulative, connecting contemporary issues with precolonial ones, across the colonial divide.

The articles in this issue attest to law's relatively recent liberation from the unitary frameworks that have constrained area studies, nation-states, and even social theory itself, since the end of the Second World War. Subsequently, the end of the Cold War, which had locked populations down within nations arranged on each side of that divide, inspired new waves of scholarship on transnationalism, globalization, diaspora, and maritime history, and a renewed interest in imperialism. As legal historians are joining this roving band in growing numbers, it would be useful to reflect on how law has been a part of this historical trajectory, and shaped it in profound ways. Inspired by the rich and innovative set of articles in this issue, this piece attempts to do that.

Upon decolonization, law provided the essential frame for the formation of newly independent states. Law enabled the articulation of national sovereignty and the claiming of jurisdiction over territory. Whereas native sovereignty had been unbundled under colonial indirect rule, all the sticks of sovereignty were bundled up together again, upon independence. Beyond the state, law's own self-regard in fashioning a constitution for the polity by fiat on paper, defining its members and their rights and obligations, providing the containing parameters that a polity must exist within, and rules for its operation, the adjudication of disputes within it, and the use of force to maintain all of these, are attempts to create a society for a state.

In hindsight, the moment of independence was probably the point at which the sticks of sovereignty were most tightly gathered together. Subsequently, and with greater force after the demise of the Soviet Union, the bundle would be loosened, as the International Monetary Fund (IMF) imposed economic conditions, global deregulation broke down financial and tariff walls, and arbitration contracts put sovereign states at the same level as transnational corporations, suspending sovereign legal jurisdiction in those cases. These states' own subjects, in search of better lives in hard currency countries, migrated and became other sovereigns' citizens, subject to other laws, and are now called "diasporas" by 
social scientists. Territorial sovereignty is no longer as singular and encompassing as it was upon independence.

The articles in this issue look back at the period before independence, to an Indian Ocean largely under British imperial rule. In doing so, they approach legal history with fresh eyes, and present a wealth of material and perspectives that break down the sort of unitary frame that has been law's job to erect. How they do so has parallels and lessons for area studies, methodological nationalism, and social theory. Transnationalism, globalization, and diaspora pushed away from such unitary frames, but as a result, holistic and synthetic views have been lost and not replaced. The antifoundational, postmodernist American scholarship of the 1990s was happy to toss away synthetic or total perspectives, which were confused with totalitarianism, but lost also were intellectual resources for critical thought grounded in empirics and history, as well as in non-European languages and experience.

This set of articles is refreshing precisely because they embrace and recover those intellectual resources and forgotten oceanic histories of law. How they do so amounts to an agenda for moving away from unitary frames without falling into the fin de siècle traps of an abstract globalization or a parochial and presentist postmodernism. How does one write transregionalism that is thick, socially and historically?

With law, as with area studies and nation-states, disaggregation is a key methodological step for moving away from a unitary frame. Disaggregation is different from deconstruction. Husin's article looks at the range of sources Johor's not-yet sultan draws on to consolidate his sovereignty, including Ottoman and Meiji constitutions drawn on to create his own state constitutions, drafted by English lawyers and Malay officials in different recensions and languages. The would-be sultan travels to Turkey and Japan, countries staving off colonization by wrapping themselves in the legalistic cloaks of European sovereignty, and borrows pieces of their mantles to achieve sovereign recognition even within imperial encapsulation. Hussin follows the travels of the person and the journeys of the text, to understand how they are interwoven to constitute a sovereign persona. Methodologically, Hussin's analysis disaggregates the person of the sovereign from the constitutions that spell out his sovereignty. This frees the person and the texts to travel and commingle with other persons and texts. The disaggregation of person and text allows these components of sovereignty to travel, separately and together.

Disaggregation enables mobility. That mobility gives the person the ability to mix with sovereigns - English, Ottoman, Japanese, Hawaiian - and to appear as one through repeated co-presences with equals, making him a token of a class. The mobility of the constitutional texts moves the drafts 
through the hands of lawyers and administrators, persons who sift and sort jurisdictions and obligations, subsuming particular to general, inferior under superior, the stuff of sovereignty at work. The mobility of persons and texts also allows the analysis to bring into play the multiple contexts and arenas that have bearing on the perfomance, perception, and actualization of standing and sovereignty. The late nineteenth century is a time when the Ottomans are on the back foot and the Siamese monarch deftly keeps at bay would-be European colonizers, while the Japanese defeat the Russians and are accorded honorary European status. All the while, European powers were hastening territorial acquisitions while subscribing to fancy theories of indirect rule and native sovereignty. By disaggregating sovereignty, allowing its components to be mobile, and following their itineraries, the analysis taps into the multiple contexts that can be brought into play, across the world, in performing and constituting sovereignty in one small corner of the world, Johor at the tip of the Malay peninsula under British suzerainty. That those multiple contexts can speak to each other in the action of the Johor sultan also says something about the nature of international relations in the period between the Berlin Conference of 1885, when the European powers agreed not to step on each others' toes as they competitively engorged native territories, and the outbreak of the First World War, when the contradictions of free-trade, imperial monopolies came to a head. Between Berlin 1885 and Sarajevo 1914, a world that was both more free and less so gave would-be sovereigns, such as the son of a Johor nobleman, a unique historical chance to become sovereign sultans if they understood how that world was spinning, and plunged with gusto into the swirl.

Through a methodology that employs disaggregation, mobility, and multiple contexts, finally to reaggregate them, Hussin brings together beautifully otherwise disparate materials that were all marshalled, and successfully so, by the sophisticated sultan of Johor, as a repertoire. In more conventional hands, a smaller subset of this material would have resulted in yet another demonstration of the mundane verities of the invention of tradition or of deconstruction. Such conventional analyses uncannily reflect the imperial ideology that sovereign legitimacy stems from the inside of a society. In contrast, the sort of analysis that Hussin engages in allows one to understand how social entities can be constituted or transformed from the outside in.

A number of other methodological innovations characterize the articles in this set, and represent methods and concepts that can contribute to a thick transregionalism. Fahad Bishara's contribution, Paper Routes, exemplifies some of them. The article is geographically bold and ambitious, bringing together material from three major land masses: East Africa, 
Arabia, and India. Such a move usually raises red flags among dissertation committees for being sprawling and infeasible. However, Bishara is able to bring them together in a succinct and concise way, by focusing on the pieces of paper that were actually used to connect these three regions: the legal documents that record commercial transactions among them. These regions are connected by the western Indian Ocean, through the boats that plied its monsoons; their differential natural endowments gave rise to a triangular trade such as of dates from Arabia, cloth from India, and mangrove poles from East Africa. Beyond the resource complementarities, social obligations were created that guaranteed the continued existence of those exchanges, in the form of debt. Credit was extended from India to East Africa and the Persian Gulf, enabling workers to live between work seasons such as in pearl fishing, and triggering the supply of pearls, ivory, and slaves in the return direction. These obligations drew together persons of different religions, cultures, and languages, who employed a common format of Islamic legal documents written in the Arabic language to record their transactions. This transregional system of exchange and documentation predated European rule, and expanded greatly as new Western markets opened up for pearls and ivory, and demand for slaves expanded. Even as the British suppressed elements of this economy, chasing down gun runners and slave smugglers, they enabled its expansion through demand for its products, and finance for its extension into new regions. In the late nineteenth century, ever more credit came into East Africa from India, prying loose ivory and slaves from places ever deeper in the African interior. Slaves themselves and elderly women jumped into the action, pawning properties to raise cash to finance the inland trade. These colonial-era activities generated even more of the pre-existing system of Arabic-Islamic paperwork, as new financial instruments were created, jurists in the interior of Oman were called upon to make pronouncements on their legality, and many registered their documents with the colonial authorities to secure their rights under a newly developing, English appellate court structure.

Bishara's article paints an unusually thick picture of these transregional connections. A willingness to suspend commitment to a whole local society in each place, in exchange for following partial groupings, as they create and discharge obligations with counterparties across the ocean rather than close by next door, allows Bishara to perceive a larger, connected, transregional whole, tying together financiers, supervisors, and indentured labor across the ocean. The incompleteness of partial societies makes one look for their counterparts elsewhere, and makes one alert to the transregional connections that they may be a part of, even if those links are difficult to see. As those connections develop and perdure, money, credit and goods circulate among the partial groupings, over time giving rise to a 
dense network of social relations across the ocean, between regions. Continued circulation over time gives rise to the idea of a society, one that can perdure through time and across distant spaces. Indeed, the Enlightenment social theorists replaced the vertical hierarchies of divine rule with the horizontal patterns of circulation, inspired by Harvey's discovery of the blood system, to create concepts of society that were flat and egalitarian, yet natural and necessary in their own right.

The concepts of connections between partial societies, tied by circulatory exchanges, allow Bishara to construct a vision of oceanic society not dependent upon European archives for material, or upon European political structures for interpretive frames. Rather, Islamic law provided the intellectual infrastructure for a system of documentation shared by different religions, cultures, and languages, and of trade that scandalously needed no heavily armed navy to provide security and justice. Such a system did not subsist under abstract conditions of globalization, or within very local communities of trust. Rather, the western Indian Ocean provided a transregional platform that was intermediate in scale. It is material from this scale that is generating the sorts of innovative new studies that can be both transregional and thick.

Even as these two articles demonstrate how mobile methods can thicken the analysis, other articles explain why law is pushed to be mobile in the first place. Julia Stephens's Uncertain Inheritance presents a counterintuitive argument: uncertainty, rather than certainty, is what fuels litigants to press on with their cases. They do this even to multiple jurisdictions, hoping to increase their chances of a favorable outcome. One could say that law's inefficiency, rather than efficiency, provokes more demands for its services, in more places. It is not laws, but specific outcomes, that people want. On the supply side, ambiguity causes more laws to be written in efforts to close gaps in interpretation. Not only do litigants forum shop, judicial fora such as the Privy Council themselves shop, Rohit De argues, to preserve or extend their relevance. And where laws do not reach, people may seek to have them extended, as Riyad Koya shows. Fijian-Indian Muslims pressed for Anglo-Muhammadan law to be extended from the subcontinent to the further colonies such as Fiji.

This range of desires for law to be mobile demonstrates clearly that law cannot be easily shoe-horned into a frame of domination and resistance. If imperial law means domination or oppression, why do subjects clamor for their imposition? Instead of running away from law, some natives seek ever more engagement with it, these articles show. Is this consent, or opportunism? Between the contrasting poles of this question, looking at the consequences of laws as they move opens up the range of answers that one can see and think with, as these articles demonstrate. 
In sum, the time is ripe now for studies that do not assume the unitary frames of society-state isomorphism. Disaggregating such categories enables their components to move, separately, and to engage with multiple contexts as they do so. Mobile elements do not necessarily lead to sprawling accounts. Rather, if properly conceptualized, they can illuminate the social relationships that connect transregionally over long distances. Such relationships perdure if they are sustained by circulations of gifts, communications, and visits. They are recognizable in the first place only if one is willing to work with societies that are considered partial rather than full societies. With such a methodological approach in mind, one is often able to discover veins of data that speak to connections with other regions, data that were not seen or were ignored earlier simply because we did not understand the mobile and circulatory processes that generated them in the first place, historically. Such veins tend to exist at the intermediate level, rather than at global or local ones. The articles in this special issue demonstrate convincingly that such veins of data do exist, and are worth bringing to light with analyses attentive to the mobile dimensions of law and its practice. Properly conducted, such analyses can circle back to revamp our understanding of the unitary society-state by casting new light upon it, now from the outside in. 